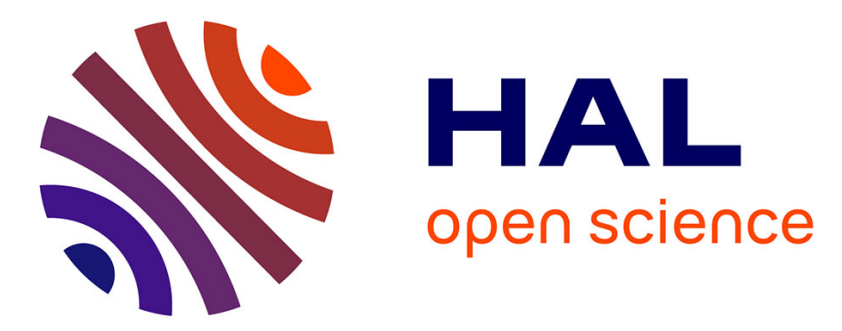

\title{
A new leaky piston identification method in an axial piston pump based on the extended Kalman filter
}

\author{
D. Bensaad, A. Soualhi, F. Guillet
}

\section{To cite this version:}

D. Bensaad, A. Soualhi, F. Guillet. A new leaky piston identification method in an axial piston pump based on the extended Kalman filter. Measurement - Journal of the International Measurement Confederation (IMEKO), 2019, 148, pp.106921 -. 10.1016/j.measurement.2019.106921 . hal-03487768

\section{HAL Id: hal-03487768 \\ https://hal.science/hal-03487768}

Submitted on 20 Dec 2021

HAL is a multi-disciplinary open access archive for the deposit and dissemination of scientific research documents, whether they are published or not. The documents may come from teaching and research institutions in France or abroad, or from public or private research centers.
L'archive ouverte pluridisciplinaire HAL, est destinée au dépôt et à la diffusion de documents scientifiques de niveau recherche, publiés ou non, émanant des établissements d'enseignement et de recherche français ou étrangers, des laboratoires publics ou privés.

\section{다)(1) $(5$}

Distributed under a Creative Commons Attribution - NonCommercial| 4.0 International 


\title{
A new leaky piston identification method in an axial piston pump based on the extended Kalman filter
}

\author{
D. Bensaad ${ }^{\mathrm{a}, *}$, A. Soualhi ${ }^{\mathrm{a}}$, F. Guillet ${ }^{\mathrm{a}}$ \\ aUniv Lyon, Université Jean Monnet, Laspi, IUT de Roanne, F-42023, Saint Etienne, France
}

\begin{abstract}
Volumetric losses are essential to ensure proper lubrication of moving components in an axial piston pump (APP). However, amplification of these volumetric losses can be observed when one or more pistons of the APP degrade due to friction and contaminated fluid. This amplification of volumetric losses due to a worn piston is often called a piston leak. The latter disturbs the output pressure signal and considerably reduces the efficiency of the pump. It also generates significant vibrations that can lead to the resonance of the pump structure. In this context, it is necessary to implement a diagnosis tool to identify the worn piston among the others. This will allow effective maintenance interventions by changing only the worn piston instead of all pistons.

This paper presents a new approach based on the physical model of the pump to identify the worn piston from the healthy ones. It begins by modelling the dynamic comportment of the pump in a nonlinear state model. Then, the extended Kalman filter (EKF) is adapted to estimate pressure in piston chambers. This estimation gives the possibility to observe the pressure into each piston chamber and then allows the identification of the worn piston. The proposed approach is validated on an APP test rig. The obtained results prove the efficiency of the proposed approach in identifying the worn piston.
\end{abstract}

Key words: Axial piston pump; piston leak; extended kalman filter; fault diagnosis

\section{Introduction}

The axial piston pump (APP) is a fundamental component in power hydraulic systems. Compared to other hydrostatic pumps, APP presents more advantages especially in high pressure operating conditions. Indeed, it offers the best efficiency due to its cylindrical displacement chambers that does not require complicated seals. Unfortunately, working under high pressure makes the APP subject to the apparition of faults causing efficiency decrease and ultimately total breakdown. Hence, implementing efficient detection and diagnosis techniques is essential to improve pump reliability and save important maintenance costs.

Different types of fault can occure on an APP; among them we can find cavitation [1], piston crack [2, 3], bearing faults [4], variable mechanism fault [5], rotor wear [6], abrasion of valve plate [7], abrasion of slipper $[8,9,10]$, loose slipper fault [11]. The occurrence of each type of fault depends on the application and the design of the pump. However, one important aspect of fault did not receive enough attention from researchers, namely internal leakages. Indeed, most of the studies carried out on this topic concern the mathematical modelling of leakages $[12,13]$ while fewer works were addressed to the problem of internal leakages diagnosis $[14,15,16]$. The present paper focuses on the diagnosis of one type of internal leakages, namely piston leak.

\footnotetext{
${ }^{*}$ Corresponding author

Email addresses: d.bensaad@univ-st-etienne.fr (D. Bensaad ), abdenour.soualhi@univ-st-etienne.fr (A. Soualhi ), guillet@univ-st-etienne.fr (F. Guillet)
} 
Piston leak occurs between two components of the pump: the piston and the barrel. It is the result of friction forces applied on the piston cylindrical surface and the cylinder bore surface [17]. The degradation of these two surfaces increase the clearance between them and creates more leakage flow. This phenomenon can be accelerated and localized on a single piston when the fluid is contaminated with debris. Indeed, APP installations do not contain suction filtration, which allows sometimes the debris contained in the tank to pass through the pump. This passage of debris accelerates the surface degradation creating important piston leaks. Figure 1 explains this degradation process. The consequence of a piston leak is a decrease in the pump's efficiency as well as an increase in the pump structure vibration.

In term of measured signal, the leakage introduces a periodic drop in the output pressure signal of the pump. Conventional signal-based diagnosis methods are able to detect the presence of a piston leak [14, 15]. For instance, a simple spectral analysis shows an increase in the amplitude of the rotation frequency. However, these methods are unable to identify the leaky piston among the good ones. To overcome this limitation, a new model-based diagnosis approach is proposed to identity the leaky piston. Based on the proposed approach, an effective maintenance intervention is possible by changing only the worn piston.

Fault diagnosis techniques can be classified into three main categories depending on the approach nature [18]. Hence, we find signal-based, model-based and knowledge-based approaches' [19]. In this paper, we focus on model-based approach for two reasons. It offers a good physical understanding of the fault occurrence and requires small amounts of data. The basic principle of model-based diagnosis approach is to compare between the measured system outputs and the predicted ones [18]. This comparison generates residuals used to make the diagnosis decision. The Kalman filter is one among the most used tools in model-based fault diagnosis techniques [20]. Originally formulated for linear systems [21], its use became more common with its extension to nonlinear systems, the extended Kalman filter (EKF). Usually, linear form is limited in describing the dynamics of a physical system. This is the case of axial piston pump which is commonly modeled by nonlinear equations. In the present paper, the EKF is adapted to identify the leaky piston in an APP by considering cylinder bores pressures and the pump output pressure as state variables. Then, a residual signal is calculated from the pressure estimates to make the diagnosis decision.

The rest of this article is organized into 5 sections. Section 2 presents the mathematical modelling of an APP by both algebraic and differential equations. The modelling of different types of internal leakages is also given in order to achieve simulation of leakage faults. Section 3 recalls fundamental equations of the EKF and details the proposed implementation of it as a leak detector filter. Section 4 describes the HYDAC APP test bench used

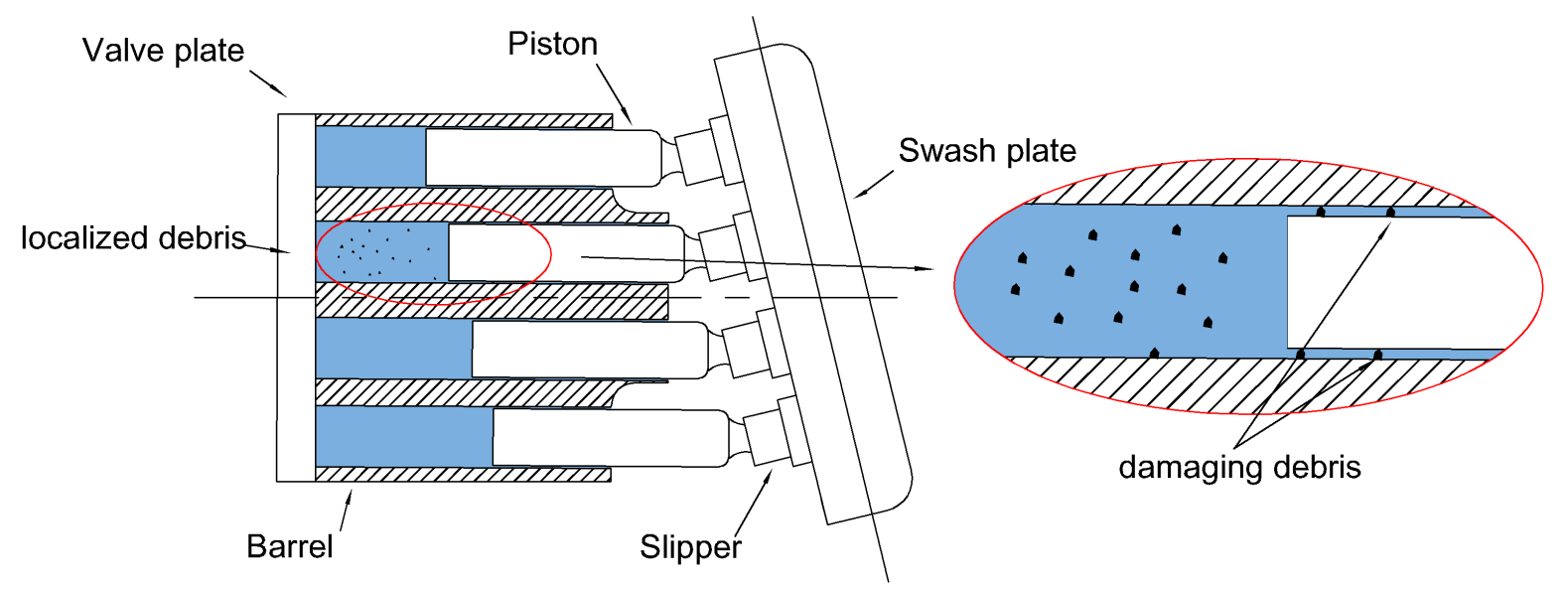

Figure 1: Degradation of the piston surface in presence of debris. 
to perform experimental tests. Section 5 presents the methodology and results of the leaky piston identification method. Finally, a conclusion is presented in Section 6.

\section{Mathematical modelling}

In a model-based diagnosis approach, the model must represent the system under investigation [18]. Therefore, the following model reflects the experimental test bench presented in section 4 and its hydraulic circuit presented in figure 2. According to [13], an APP can be modeled by the following equations:

$$
\begin{gathered}
\frac{d P_{i}}{d t}=\frac{B}{V_{i}}\left(Q_{g, i}+Q_{i n, i}-Q_{d, i}-Q_{l, i}\right) \\
V_{i}=V_{0}-A_{p} \cdot R \cdot \tan (\beta)\left(1-\cos \left(\varphi_{i}\right)\right) \\
Q_{g, i}=-\frac{d V_{i}}{d t}=A_{p} \cdot R \cdot \omega \cdot \tan (\beta) \cdot \sin \left(\varphi_{i}\right) \\
Q_{d, i}=A_{d, i} \cdot C_{d \cdot} \sqrt{\frac{2\left|P_{i}-P_{d}\right|}{\rho}} \cdot \operatorname{sgn}\left(P_{i}-P_{d}\right) \\
Q_{i n, i}=A_{i n, i} \cdot C_{d} \cdot \sqrt{\frac{2\left|P_{i n}-P_{i}\right|}{\rho}} \cdot \operatorname{sgn}\left(P_{i n}-P_{i}\right)
\end{gathered}
$$

where:

- $P_{i}, P_{d}$ and $P_{i n}$ are respectively the instantaneous pressure in the $i$ th piston chamber, the discharge chamber pressure and the intake chamber pressure;

- $V_{i}$ is the volume in the $i$ th piston chamber and $V_{0}$ is the initial volume of the piston chamber when the piston is at the bottom dead center (BDC) position. The latter corresponds to the farthest piston position form the valve plate (see figure 3);

- $Q_{g, i}, Q_{d, i}, Q_{i n, i}$ and $Q_{l, i}$ are respectively the geometry flow created by the $i$ th piston motion, the discharge flow that goes from the $i$ th piston chamber to the discharge chamber, the intake flow that goes from the intake chamber to the $i$ th piston chamber and the total leakage flow of the $i$ th piston;

- $A_{p}, A_{d, i}$ and $A_{i n, i}$ are respectively the piston cross-section area, the intake area and the discharge area of the $i$ th piston. The area $A_{d}$ and $A_{i n}$ result from the passage of the cylinder port through the suction port and the discharge port of the valve plate;

- The parameters $B, C_{d}$ and $\rho$ define the characteristics of the fluid. They represent respectively the fluid bulk modulus, the discharge cœfficient and the fluid density;

- $R, \beta, \varphi_{i}$ and $\omega$ define respectively the piston pitch radius, the inclination angle of the swash plate, the angular position of the piston and the angular velocity of the drive shaft. The last two parameters depend on each other by the relation $\varphi_{i}=\omega t-(i-1) \alpha$ in which $\alpha$ is the piston offset angle, $i$ is the piston number and $t$ is the time instant;

- |.| stands for the absolute value symbol and $\operatorname{sgn}($.$) for the sign \operatorname{symbol}$. For a real number $x, \operatorname{sgn}(x)=-1$ if $x<0, \operatorname{sgn}(x)=0$ if $x=0$ and $\operatorname{sgn}(x)=1$ if $x>0$. 


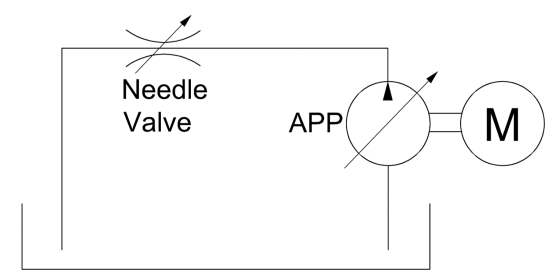

Figure 2: Hydraulic circuit of the test bench.

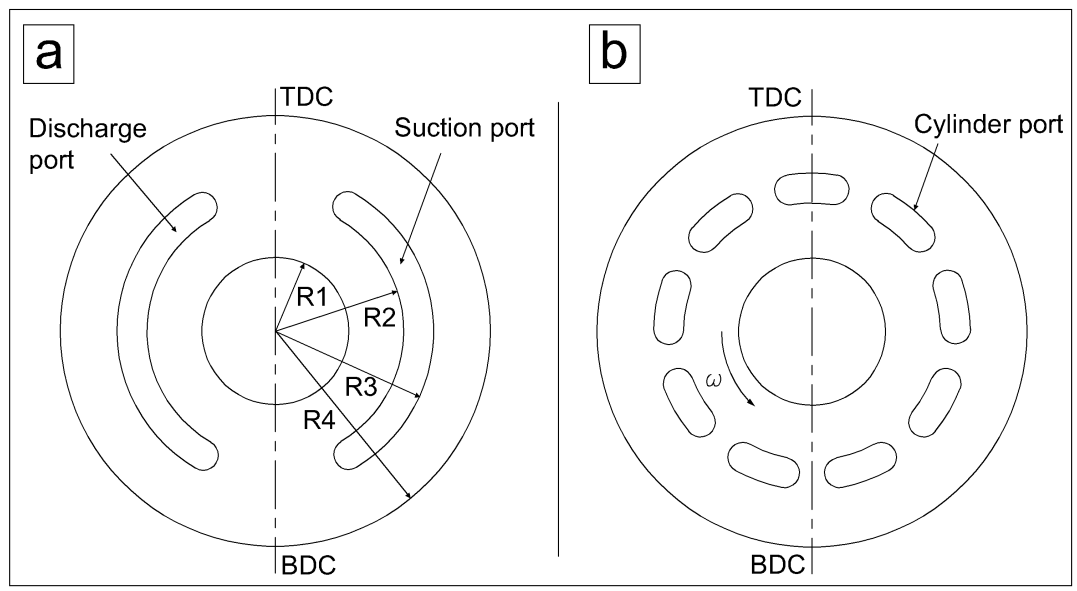

Figure 3: Standard design of: (a) valve plate, (b) barrel.

The total leakage flow denoted by $Q_{l, i}$ in equation (1) is the sum of all internal leakages. Figure 4 shows the four different leakages that can be found in our APP: leakage L1 between the piston and barrel, which is the focus of our work, leakage L2 between the slipper and swash plate, leakage L3 between the piston and slipper, and finally leakage L4 between the valve plate and barrel. The corresponding flow generated by these leakages are denoted respectively by $Q_{1}, Q_{2}, Q_{3}$ and $Q_{4}$.

Among all leakages, L3 is the smallest because most of the fluid going through the bottom hole of the piston goes through the slipper hole making leakage L2. Hence, leakage L3 is not considered in this study. The flow generated by leakages L1, L2 and L4 can be expressed as follows:

$$
\begin{gathered}
Q_{1, i}=\frac{\pi \cdot d_{p} \cdot \delta_{p}^{3}}{12 \cdot \mu \cdot l_{k}}\left(P_{i}-P_{0}\right) \\
Q_{2, i}=\frac{\pi \cdot d_{h}^{4} \cdot \delta_{s}^{3}}{\mu\left(6 \cdot d_{h}^{4} \cdot \ln \left(\frac{R_{s}}{r_{s}}\right)+128 \cdot \delta_{s}^{3} \cdot l_{p}\right)}\left(P_{i}-P_{0}\right) \\
Q_{4, i}=\frac{\delta_{v}^{3}}{12 \cdot \mu}\left[\frac{1}{\ln \left(\frac{R_{2}}{R_{1}}\right)}+\frac{1}{\ln \left(\frac{R_{4}}{R_{3}}\right)}\right]\left(P_{i}-P_{0}\right)
\end{gathered}
$$


where:

- $\delta_{p}, \delta_{s}$ and $\delta_{v}$ are respectively the clearance between the piston and cylinder block, the clearance between the slipper and swash plate and the clearance between the valve plate and barrel.

- $d_{h}, R_{s}, r_{s}$ are respectively the diameter of the piston bottom hole, the outer and the inner radius of the slipper.

- $l_{p}, l_{k}$ are respectively the piston length and the instantaneous gap length giving by $l_{k}=l_{a}+s_{k}$, where $l_{a}$ is the initial gap length when the piston is at BDC and $s_{k}$ is the piston displacement giving by $s_{k}=$ $R \tan \beta(1-\cos \varphi)$.

- $P_{0}$ and $\mu$ are respectively the pressure in the pump sump and the kinetic viscosity of the fluid.

- $R 1, R 2, R 3, R 4$ are related to the valve plate dimensions. They are shown in Figure 3.

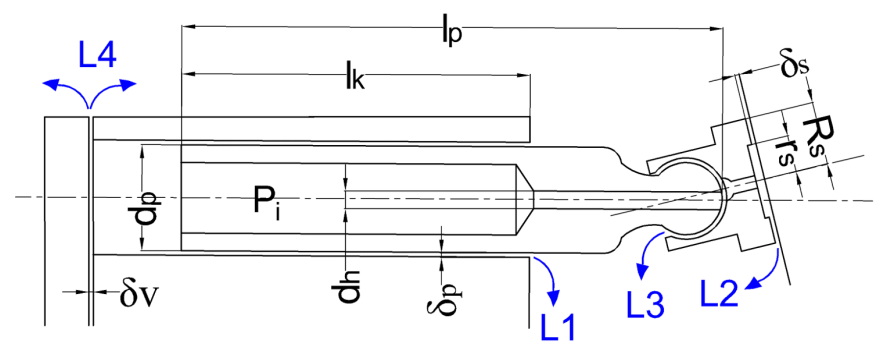

Figure 4: Different internal leakages in an APP.

Considering the hydraulic circuit shown in Figure 2, the discharge chamber pressure can be expressed as follows:

$$
\frac{d P_{d}}{d t}=\frac{B}{V_{d}}\left(Q_{t d}-Q_{v}\right)
$$

where $Q_{t d}=\sum_{i=1}^{n} Q_{d i}$ is the total resulting discharge flow from all the pistons, $n$ is the number of pistons, $Q_{v}$ is the flow rate through the needle valve and $V_{d}$ is the discharge chamber volume. The flow rate through the needle valve $Q_{v}$ can be expressed by the following equation:

$$
Q_{v}=C_{v} \cdot A_{v} \sqrt{\frac{2\left(P_{d}-P_{t}\right)}{\rho}}
$$

where $C_{v}$ is the discharge coefficient of the needle valve, $A_{v}$ is the needle valve discharge area and $P_{t}$ is the tank pressure.

The diagnosis method presented in this paper is based on estimating piston chamber pressures and the output pressure of the pump. This estimation is performed with the discrete EKF. Therefore, the model described by equations from (1) to (10) is written in a discrete state-space form in the next section.

\section{Pressure estimations with the EKF}

The occurrence of a piston leak introduces a periodic drop in the pump output pressure signal (see figure 5). From the latter, it is not possible to directly identify the worn piston. Therefore, we propose to estimate pressures 
inside each piston chamber with the EKF to capture the exact moment of full connection between the cylinder port and the discharge port of the valve plate. This moment corresponds to the pressure drop beginning which will lead us to identify the leaky piston in section 5. The EKF is chosen instead of the KF because this latter is a linear filter while the pump mathematical model is nonlinear. Therefore, the EKF is the suited filter in our case because it can deal with nonlinear systems.


Figure 5: Output pressure variation over one period in presence of a piston leak.

The general form of the EKF is given in [22] for a nonlinear system. It is described as follows:

$$
\left\{\begin{array}{l}
x_{k}=f\left(x_{k-1}, u_{k}, w_{k-1}\right) \\
z_{k}=h\left(x_{k}, v_{k}\right)
\end{array}\right.
$$

The nonlinear function $f$ in equation (11) relates the state $x_{k}$ to the previous time step state $x_{k-1}$, to a driving function $u_{k}$ and to the zero mean process noise $w_{k-1}$. In equation (12), $h$ is a nonlinear function that relates the measurement $z_{k}$ to the state $x_{k}$ and the measurement noise $v_{k}$. In our application, no driving function $u_{k}$ is included, hence it will not be taken into consideration in further developments.

The EKF equations can be divided into two stages: the prediction stage that contains time update equations (13) and (14) and the correction stage that contains measurement update equations (15)-(17).

$$
\begin{gathered}
\left\{\begin{array}{l}
\hat{x}_{k}^{-}=f\left(\hat{x}_{k-1}, 0\right) \\
P_{k}^{-}=A_{k} P_{k-1} A_{k}^{T}+W_{k} Q_{k-1} W_{k}^{T}
\end{array}\right. \\
\left\{\begin{array}{l}
K_{k}=P_{k}^{-} H_{k}^{T}\left(H_{k} P_{k}^{-} H_{k}^{T}+V_{k} R_{k} V_{k}^{T}\right)^{-1} \\
\hat{x}_{k}=\hat{x}_{k}^{-}+K_{k}\left(z_{k}-h\left(\hat{x}_{k}^{-}, 0\right)\right) \\
P_{k}=\left(I-K_{k} H_{k}\right) P_{k}^{-}
\end{array}\right.
\end{gathered}
$$

$\hat{x}_{k}^{-}$and $\hat{x}_{k}$ are the a priori and a posteriori state estimates at step $k$, respectively, giving knowledge to the process and the measurement $z_{k} . K_{k}$ is the Kalman gain. $P_{k}^{-}$and $P_{k}$ are the a priori and a posteriori estimate error covariances. $Q_{k}$ and $R_{k}$ are the process noise covariance and measurement noise covariance, respectively. $A_{k}$, $H_{k}, W_{k}, V_{k}$ are the Jacobian matrices of partial derivatives of $f$ and $h$ with respect to $x, w$ and $v$. They are given 
by the following equations:

$$
A_{k[i, j]}=\frac{\partial f_{[i]}}{\partial x_{[j]}}\left(\hat{x}_{k-1}, 0\right), \quad W_{k[i, j]}=\frac{\partial f_{[i]}}{\partial w_{[j]}}\left(\hat{x}_{k-1}, 0\right), \quad H_{k[i, j]}=\frac{\partial h_{[i]}}{\partial x_{[j]}}\left(\hat{x}_{k}^{-}, 0\right), \quad V_{k[i, j]}=\frac{\partial h_{[i]}}{\partial v_{[j]}}\left(\hat{x}_{k}^{-}, 0\right)
$$

In order to perform estimations of the piston chamber pressures and the output pressure, the model described by equations from (1) to (10) must be written in state-space form. Firstly, we define the following state vector $x_{k}=\left[x_{1}(k), \ldots, x_{n+1}(k)\right]^{T}=\left[P_{1}, \ldots, P_{n}, P_{d}\right]^{T}$ where $P_{1}$ to $P_{n}$ correspond to pressures inside the $n$ pistons of the pump and $P_{d}$ is the output pressure of the pump. After that, we define the measurement vector as the output pressure signal of the pump, thus $z_{k}=\left[P_{d}\right]^{T}$. Then, for the $i$ th piston, we express equations from (4) to (8) as follows:

$$
\begin{gathered}
Q_{d, i}(k)=A_{d, i}(k) \cdot C_{d} \cdot \sqrt{\frac{2\left|x_{i}(k)-x_{n+1}(k)\right|}{\rho}} \cdot \operatorname{sgn}\left(x_{i}(k)-x_{n+1}(k)\right) \\
Q_{i n, i}(k)=A_{i n, i}(k) \cdot C_{d \cdot} \sqrt{\frac{2\left|P_{i n}-x_{i}(k)\right|}{\rho}} \cdot \operatorname{sgn}\left(P_{i n}-x_{i}(k)\right) \\
Q_{1, i}(k)=\frac{\pi \cdot d_{p} \cdot \delta_{p}^{3}}{12 \cdot \mu \cdot l_{k}}\left(x_{i}(k)-P_{0}\right) \\
Q_{2, i}(k)=\frac{\pi \cdot d_{h}^{4} \cdot \delta_{s}^{3}}{\mu\left(6 \cdot d_{h}^{4} \cdot \ln \left(\frac{R_{s}}{r_{s}}\right)+128 \cdot \delta_{s}^{3} \cdot l_{p}\right)}\left(x_{i}(k)-P_{0}\right) \\
Q_{4, i}(k)=\frac{\delta_{v}^{3}}{12 \cdot \mu}\left[\frac{1}{\ln \left(\frac{R_{2}}{R_{1}}\right)}+\frac{1}{\ln \left(\frac{R_{4}}{R_{3}}\right)}\right]\left(x_{i}(k)-P_{0}\right)
\end{gathered}
$$

The total leakage flow in one piston can be written as $Q_{l, i}(k)=Q_{1, i}(k)+Q_{2, i}(k)+Q_{4, i}(k)$. Finally, the nonlinear state-space model of the system can be defined by expressing equations (1) and (9) as follows:

$$
\begin{aligned}
& \left\{\begin{array}{c}
x_{1}(k+1)=\Delta t \frac{B}{V_{1}(k)}\left[Q_{g, 1}(k)+Q_{i n, 1}(k)-Q_{d, 1}(k)-Q_{l, 1}(k)\right]+x_{1}(k) \\
\vdots \\
\vdots \\
x_{n}(k+1)=\Delta t \frac{B}{V_{n}(k)}\left[Q_{g, n}(k)+Q_{i n, n}(k)-Q_{d, n}(k)-Q_{l, n}(k)\right]+x_{n}(k) \\
x_{n+1}(k+1)=\Delta t \frac{B}{V_{d}}\left[\sum_{i=1}^{9} Q_{d, n+1}(k)-C_{v} \cdot A_{v} \sqrt{\left.\frac{2\left(x_{n+1}(k)-P_{t}\right)}{\rho}\right]}+x_{n+1}(k)\right.
\end{array}\right. \\
& z(k)=\left[\begin{array}{llll}
0 & \ldots & 0 & 1
\end{array}\right]\left[x_{1}(k) \ldots x_{n}(k) \quad x_{n+1}(k)\right]^{T}
\end{aligned}
$$

where $\Delta t$ is the sampling time.

The nonlinear process function $f$ is defined by the system of equations (24), which gives each state variable in step $(k+1)$ as a function of state variables in the previous step $(k)$. Whereas, the measurement function $h$ is given by equation (25) which relates the measurement $z_{k}$ to state vector $x_{k}$. Given the measurement $z_{k}$, for each iteration, the EKF estimates the state variables of $\hat{x}$ based on the defined state-space model of the pump, which 
in this case models a healthy system. Finally, we calculate the residual signal $e=P_{d}-\hat{P}_{d}$ which is used to make the diagnosis decision. In presence of a piston leak the residual signal increases. Whereas in the healthy case, it remain insignificant. Figure 6 shows the scheme of the EKF estimator as a leak detector. The input of the EKF is the pump output pressure. Whereas the outputs are the estimated piston chamber pressures and the estimated output pressure.

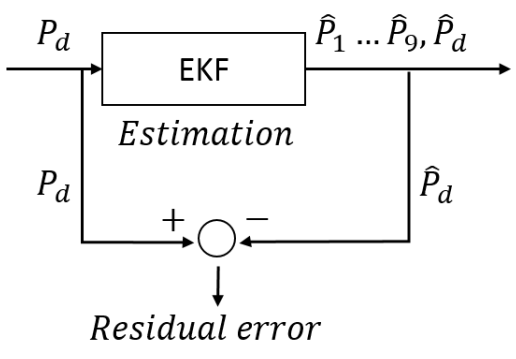

Figure 6: Extended Kalman filter leak detector scheme.

\section{Experimental setup}

\subsection{Description of the hydraulic test bench}

In order to validate the proposed approach, the experimental hydraulic test bench presented in figure 7 is used. It is mainly composed of a HYDAC PPV103-10 pump driven by an electrical motor. There is also a needle valve used as a load by changing its opening. The test bench is equipped with a frequency converter. However, the motor speed was fixed at $1200 \mathrm{rpm}$ for all the tests. The used oil is TELLUS S2 V32 with a density of $872 \mathrm{~kg} / \mathrm{m}^{3}$ and kinematic viscosity of $32 \mathrm{~mm}^{2} / \mathrm{s}$ at $40^{\circ} \mathrm{C}$.

In order to acquire the instantaneous output pressure signal, a PCB113B22 piezoelectric pressure sensor with a sensitivity of $148.6 \mathrm{mV} / \mathrm{MPa}$ is used. In addition, a voltage pressure sensor IFM PU5401 is used to give DC component of the pressure signal. Moreover, a laser tachometer is placed on the drive shaft of the pump to be used as a trigger. All the signals were acquired simultaneously using an NI 9234 acquisition card. The sampling frequency is $10240 \mathrm{~Hz}$ and the data duration is $10 \mathrm{~s}$.



Figure 7: Experimental test bench. 


\subsection{Description of the HYDAC pump}

The HYDAC pump is a 9 pistons APP. Its maximum displacement is equal to $10 \mathrm{~cm}^{3}$, which can be reached when the swash plate is at its maximum inclination. The design of this pump includes a swash plate and sliding slippers. Figure 8 shows the design details which are mainly related to the valve plate. Figure $8 \mathrm{a}$ and $8 \mathrm{~b}$ show the piston-slipper assembly and the valve plate, respectively. The discharge port of the valve plate contains three openings while the suction port contains two openings, which is not a standard valve plate design. It can be noted that the valve plate contains relief notches at the edge of each port.

The mathematical model presented in section 2 must take into consideration the valve plate design because of its influence on the simulation results $[23,24]$. Therefore, the discharge area $A_{d}$ and the intake area $A_{\text {in }}$ mentioned in equations (4) and (5) respectively, must be modelled according to the HYDAC valve plate design. The modelling of these two areas is performed using position relationships similarly to what is presented in [25]. The variations of $A_{d}$ and $A_{\text {in }}$ are shown in Figure 9.
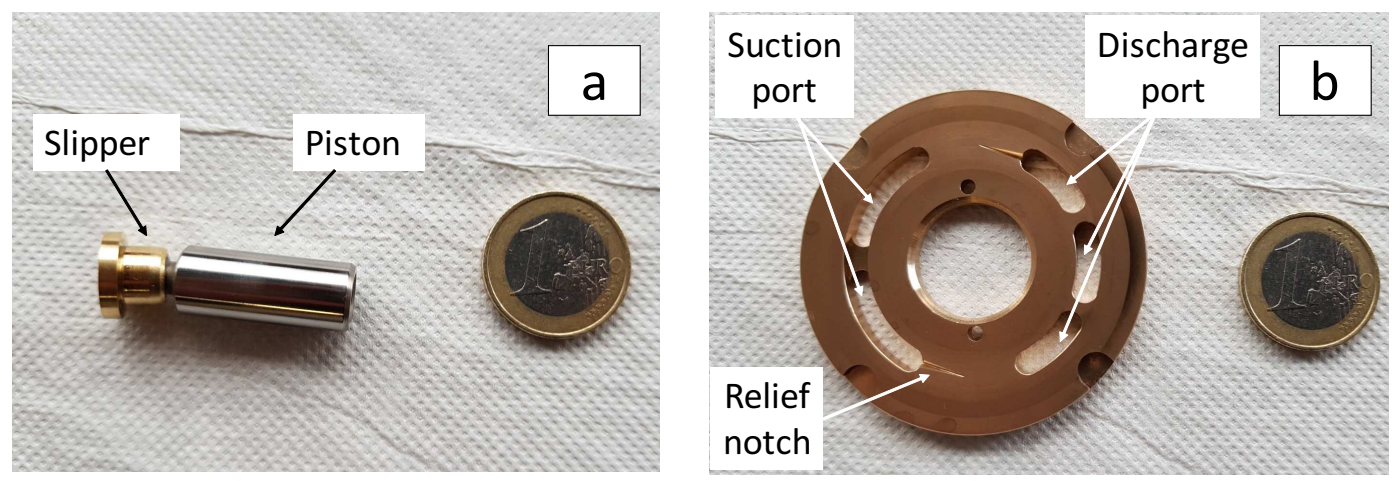

Figure 8: HYDAC pump design details: (a) Piston-slipper assembly, (b) Valve plate.

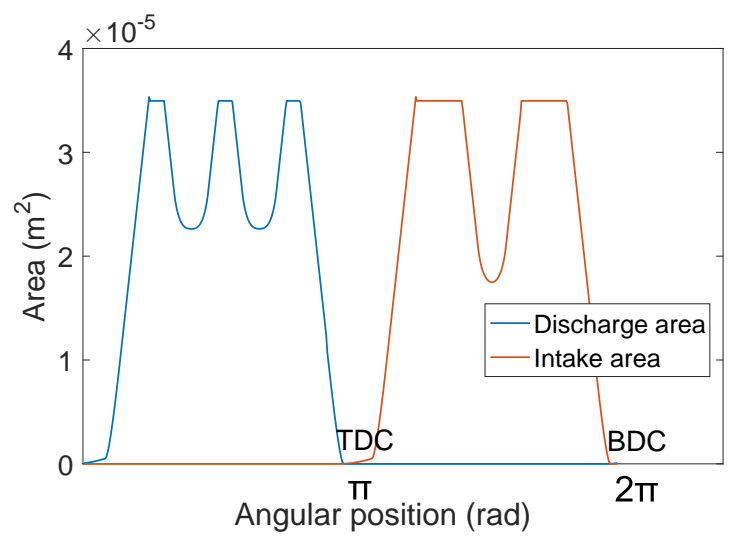

Figure 9: Discharge area and intake area variations over one shaft round. 


\section{Results and discussion}

\subsection{Comparison between simulated and real output pressure signals}

To ensure the proposed model presented in section 2 corresponds to the system under investigation, simulations of the output pressure signal are performed including parameters of the experimental system presented in section 4. The parameter values are given in Table 1, they include system dimensions and fluid properties. Differential and algebraic equations from (1) to (10) describing the model can be solved on Simulink by Euler solver with a fixed time step of $10^{-6} \mathrm{~s}$.

Figure 10 represents simulated output pressure signals from the Simulink model and real output pressure signals acquired on the experimental test bench. In order to set all the acquired signals on the same phase, the tachometer shown in Figure 7 is used. A reflective strip is placed on the same angular position as one piston. This latter is considered as the first piston in our study. The pressure sensor is placed on the discharge chamber of the pump (see figure 7). Therefore, there is no phase delay between acquired and simulated signals. The rotational speed was fixed at $1200 \mathrm{rpm}$, thus the duration of one period is $0.05 \mathrm{~s}$.

Table 1: Parameter values of the HYDAC pump model.

\begin{tabular}{cc|cc|cc|cc|cc}
\hline Symbol & value & Symbol & value & Symbol & value & Symbol & value & Symbol & value \\
\hline$\beta(\mathrm{rad})$ & 0.207 & $R(\mathrm{~m})$ & $1.9 \times 10^{-2}$ & $\omega\left(\mathrm{rad} . \mathrm{s}^{-1}\right)$ & 125.66 & $V_{0}\left(\mathrm{~m}^{3}\right)$ & $2.26 \times 10^{-6}$ & $d_{p}(\mathrm{~m})$ & $1.05 \times 10^{-2}$ \\
$C_{d}$ & 0.6 & $C_{v}$ & 0.6 & $A_{p}\left(\mathrm{~m}^{2}\right)$ & $8.66 \times 10^{-5}$ & $A_{v}\left(\mathrm{~m}^{2}\right)$ & $1.02 \times 10^{-6}$ & $\rho\left(\mathrm{kg} . \mathrm{m}^{-3}\right)$ & 872 \\
$V_{d}\left(\mathrm{~m}^{3}\right)$ & $0.06 \times 10^{-3}$ & $B(\mathrm{~Pa})$ & $1 \times 10^{9}$ & $\alpha(\mathrm{rad})$ & 0.6981 & $\mu\left(N . s . \mathrm{m}^{-2}\right)$ & $2.7 \times 10^{-2}$ & $r_{k}(\mathrm{~m})$ & $1.95 \times 10^{-3}$ \\
$l_{k}(\mathrm{~m})$ & $5.9 \times 10^{-3}$ & $R_{s}(\mathrm{~m})$ & $2.59 \times 10^{-2}$ & $r_{s}(\mathrm{~m})$ & $3.65 \times 10^{-3}$ & $l_{p}(\mathrm{~m})$ & $3.45 \times 10^{-2}$ & $R 1(\mathrm{~m})$ & $9.75 \times 10^{-3}$ \\
$R 2(\mathrm{~m})$ & $1.7 \times 10^{-2}$ & $R 3(\mathrm{~m})$ & $2.1 \times 10^{-2}$ & $R 4(\mathrm{~m})$ & $2.85 \times 10^{-2}$ & $d_{h}(\mathrm{~m})$ & $1 \times 10^{-3}$ & $P_{\text {in }}(\mathrm{Pa})$ & $1 \times 10^{5}$ \\
$\delta_{p}(\mathrm{~m})$ & $4 \times 10^{-5}$ & $\delta_{s}(\mathrm{~m})$ & $5 \times 10^{-5}$ & $\delta_{v}(\mathrm{~m})$ & $4 \times 10^{-5}$ & $P_{t}(\mathrm{~Pa})$ & 0 & $P_{0}(\mathrm{~Pa})$ & 0 \\
\hline
\end{tabular}

Figure 10a represents output pressure signals of the pump in the healthy condition. The blue line represents the simulated pressure signal and the red dotted line represents the real pressure signal. The output pressure signal is constituted by 9 ripples for one period. These ripples are visible for both real and simulated signals. They are the contribution of the 9 pistons of the pump. Nevertheless, one ripple is not the contribution of one piston. In fact, each ripple is the contribution of several pistons at the same time. Precisely, it is the contribution of all the pistons in connection with the discharge chamber of the pump at an instant $t$ [26]. Therefore, the presence of a leak in one piston will not affect only one ripple but several ones. In addition, it can be noted that the simulated pressure signal is constituted of 9 distinct ripples, while the real pressure signal contains small variations over one ripple. The form of these variations depends on the rotational speed and needle valve opening. They are created by the reverse flow generated when the needle valve is partially closed. More details concerning this phenomenon can be found in [27].

Figure $10 \mathrm{~b}$ represents real and simulated output pressure signals when the first piston is leaking. The presence of the leak creates a concave drop in the output pressure signal over one round. The leak was created by removing matter from the cylindrical surface of the piston (see Figure 11). As a result, the piston diameter is reduced by $40 \mu \mathrm{m}$. In order to generate the same fault by simulation, the parameter $\delta_{p}$ that represents the clearance between the piston and the cylinder bore in equation (6) become $\delta_{p l}=\delta_{p}+40 \mu \mathrm{m}=8 \times 10^{-5} \mathrm{~m}$. By doing so, we could achieve a good match between real and simulated output pressure signals. However, the pressure drops more quickly in the simulated signal compared to the real one. Consequently, the forms of concavities of the two pressure signals are different during the dropping phase, but they are almost similar during the recovery phase.

Figure 10c represents real and simulated output pressure signals when the third piston is leaking. This leak was created by changing the position of the worn piston described previously from the first position to the third position in the barrel, with respect to the direction of rotation. The worn piston in the third position creates the 
same concave drop in the pressure signal by being in the first position. Nevertheless, the drop beginning shifts from the zero reference by a certain value.

\subsection{Creation of modulated output pressure signals}

The real output pressure signals contain variations due to reverse flow (see figure 10). When these signals are directly used as the EKF entry, the states estimations are not good because these variations are not reproduced by the mathematical model. However, it has been shown previously that the presence of a piston leak induces a concave drop in the output pressure signal. This property can be extracted separately and added to the healthy simulated output pressure signal. Consequently, using real output pressure signal as the entry of the EKF is no longer necessary. Instead, using simulated output pressure signals containing the leak information becomes possible. For the rest of the article, we will refer inaccurately to the signals obtained by combining the simulated output pressure signals and the leak information as modulated pressure signals.

Figure 12 presents the proposed approach to create modulated pressure signals. The first step is to extract the peak envelope from the real signal. The second step is to subtract from the obtained peak envelope its maximum value. The third step is to add the peak envelope to the healthy simulated output pressure signal. The obtained signal looks like a simulated pressure signal but contains the real leak information.

Figure 13 shows a comparison between simulated pressure signals in blue lines and modulated pressure signals in red dotted lines. Figure 13a concerns the healthy pump condition. The two signals are perfectly superimposed and no difference can be distinguished. Figure 13b and figure $13 \mathrm{c}$ concern the presence of leak in the first and the third pistons, respectively. In the two cases, the concavities are different because the simulated pressure signals decrease more quickly than the modulated pressure signals.
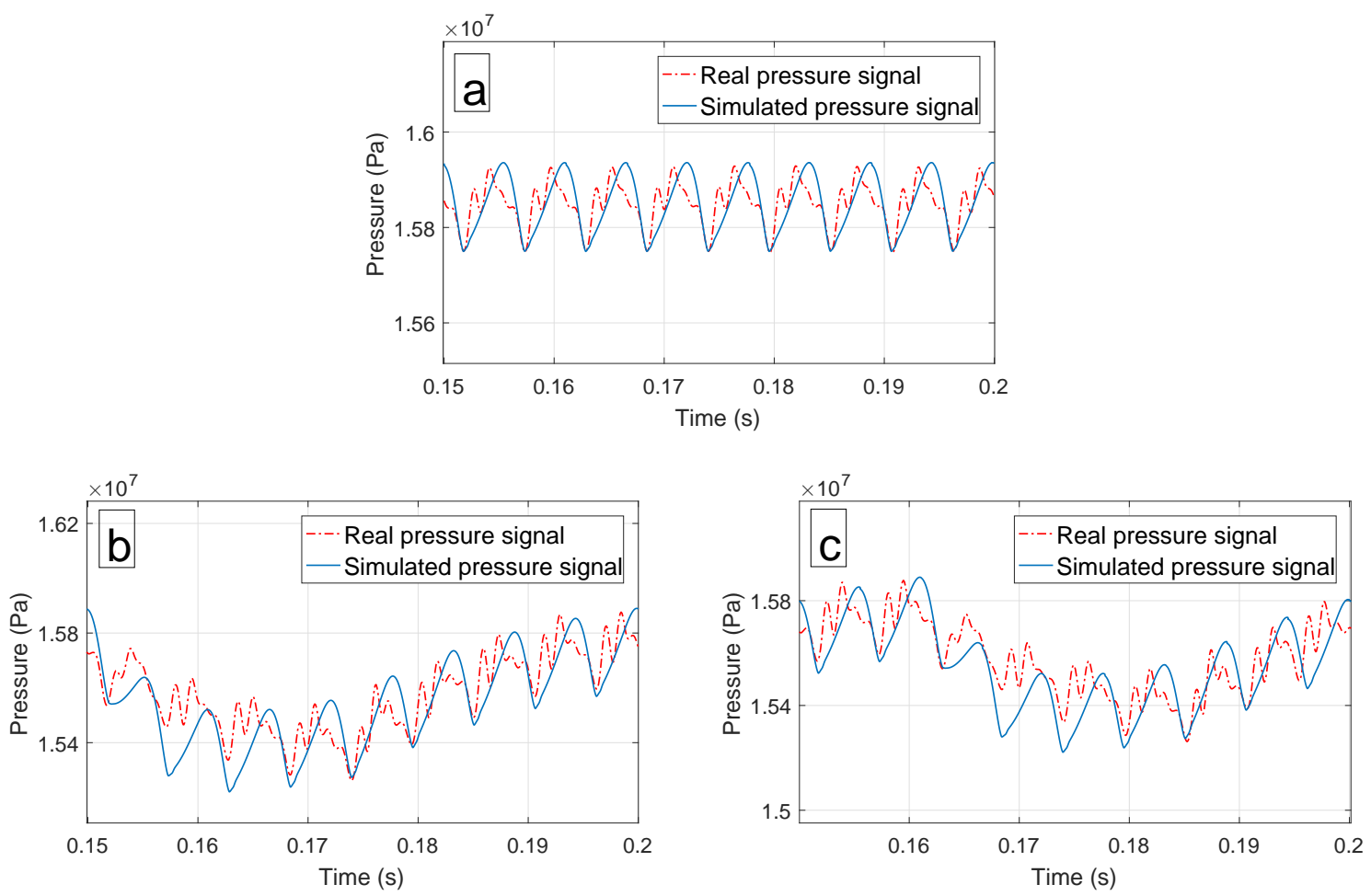

Figure 10: Real and simulated output pressure signals for: (a) healthy state, (b) piston 1 leaking, (c) p.6iston 3 leaking. 


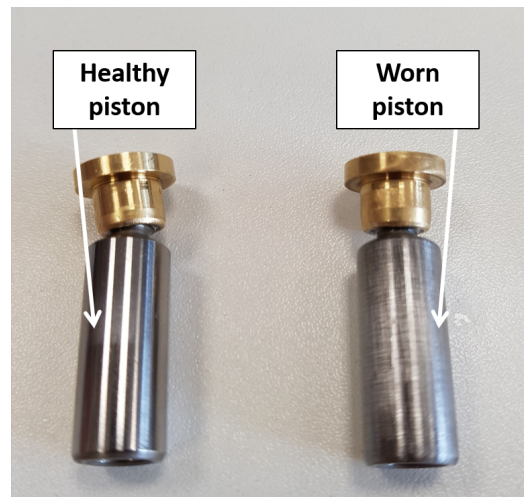

Figure 11: Healthy piston and worn piston.

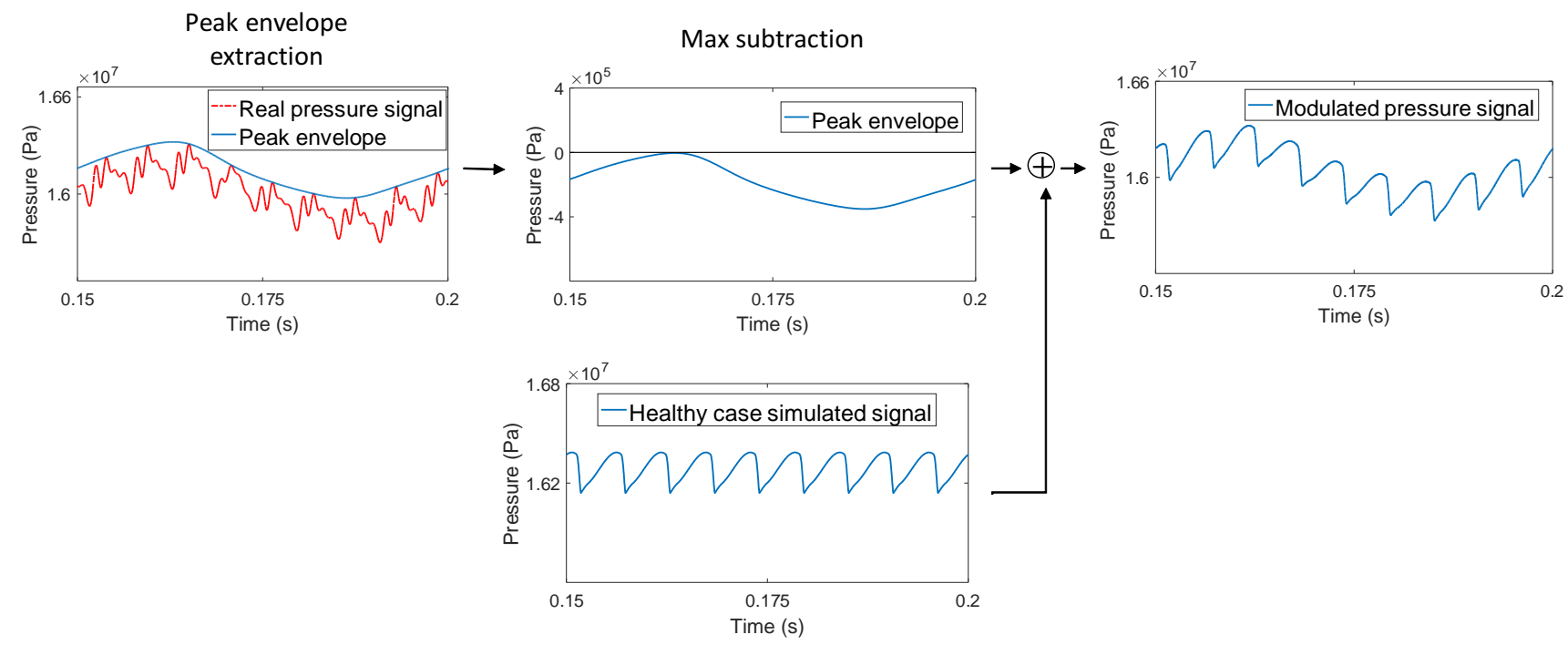

Figure 12: Creation method of the modulated output pressure signal.

\subsection{EKF adjustment}

After obtaining the modulated output pressure signals which are used as the EKF input, we must adjust the parameters of the EKF leak detector according to our system. Firstly, the Jacobians defined in equation (18) are calculated from the process function $f$ and the measurement function $h$. The matrix $A_{k}$ is obtained by Matlab function jacobian and the matrix $H_{k}$ is given by $H_{k}=\left[\begin{array}{llllllllll}0 & 0 & 0 & 0 & 0 & 0 & 0 & 0 & 0 & 1\end{array}\right]$. Secondly, assuming that process and measurement noises are white, Gaussian and stationary, the covariance matrices $Q_{k}$ and $R_{k}$ are constants. Assuming also that state variables of the system are independent from each other, then $Q_{k}$ and $R_{k}$ are diagonals. Finally, it can be deducted that the Jacobian matrices related to noises $W_{k}$ and $V_{k}$ are unity matrices.

In order to initialize the EKF, we must determine the initial values of the state vector $\hat{x}_{0}$, the initial estimation error covariance $P_{0}$, process noise covariance $Q_{k}$, and the measurement noise covariance $R_{k}$. The values of the state estimates are set to zero except for the state estimate of the output pressure which is set to a sufficiently high value, equal to $10^{5}$. The latter corresponds to the intake pressure value, thus $\hat{x}_{0}=\left[\begin{array}{lllllllllll}0 & 0 & 0 & 0 & 0 & 0 & 0 & 0 & 0 & 10^{5}\end{array}\right]$. The initial estimation error covariance $P_{0}$ is set to be a diagonal matrix where all the diagonal values are equal to $10^{2}$. Otherwise, the matrices $Q_{k}$ and $R_{k}$ are considered to be constant as it was specified earlier and will be 
noted $Q$ and $R$, respectively. In fact, $R$ contains only one component related to the noise of the output pressure measurement. Hence, $R$ is given as $R=[10]$ considering the piezoelectric signals are not noisy. Whereas $Q$ is a diagonal matrix of $10 \times 10$. Each component of the diagonal corresponds to one state variable. It was decided to set all the diagonal components of the matrix $Q$ to $10^{-9}$ which means we have extremely high confidence in the process modelling.

\subsection{Results of the EKF estimation}

The modulated pressure signals showed in figure 13 are used to achieve estimation with the EKF. The estimation results are shown in figure 14. The black lines represent the residual signal, the red lines represent the estimated pressure inside the first piston and the green dotted lines represent the estimated pressure inside the third piston. Each plot has two y axes, the right one concerns the estimated pressures and the left one concerns the residual signal. The latter is the difference between a modulated output pressure signal and an estimated one. Only pressures inside pistons one and three are shown because they are concerned by the leak tests. The variation of the pressure inside the piston is composed of two parts as it was explained in [28]. The first one concerns the aspiration phase and the second one concerns the discharge phase.

Figures 14a, 14b and 14c were obtained by using the modulated signals shown in red dotted lines in figures $13 a, 13 b$ and $13 c$ as the EKF entry. In the healthy condition, figure 14a, no change is noticeable in the residual signal. While in presence of leak in the first piston, figure $14 \mathrm{~b}$, we note an increase in the residual signal when the first piston is completely connected to the discharge chamber. This event happens at the instant shown by the black dotted line in figure 14b. It corresponds to the instant when the entire surface of the cylinder port is connected to the discharge port of the valve plate. Similarly, in presence of leak in the third piston, figure $14 \mathrm{c}$, we note an increase in the residual signal when the third piston is completely connected to the discharge chamber. Finally, it can be concluded that the residual signal increases when the leaky piston is fully connected to the discharge chamber of the pump, offering an efficient method to identify the leaky piston.
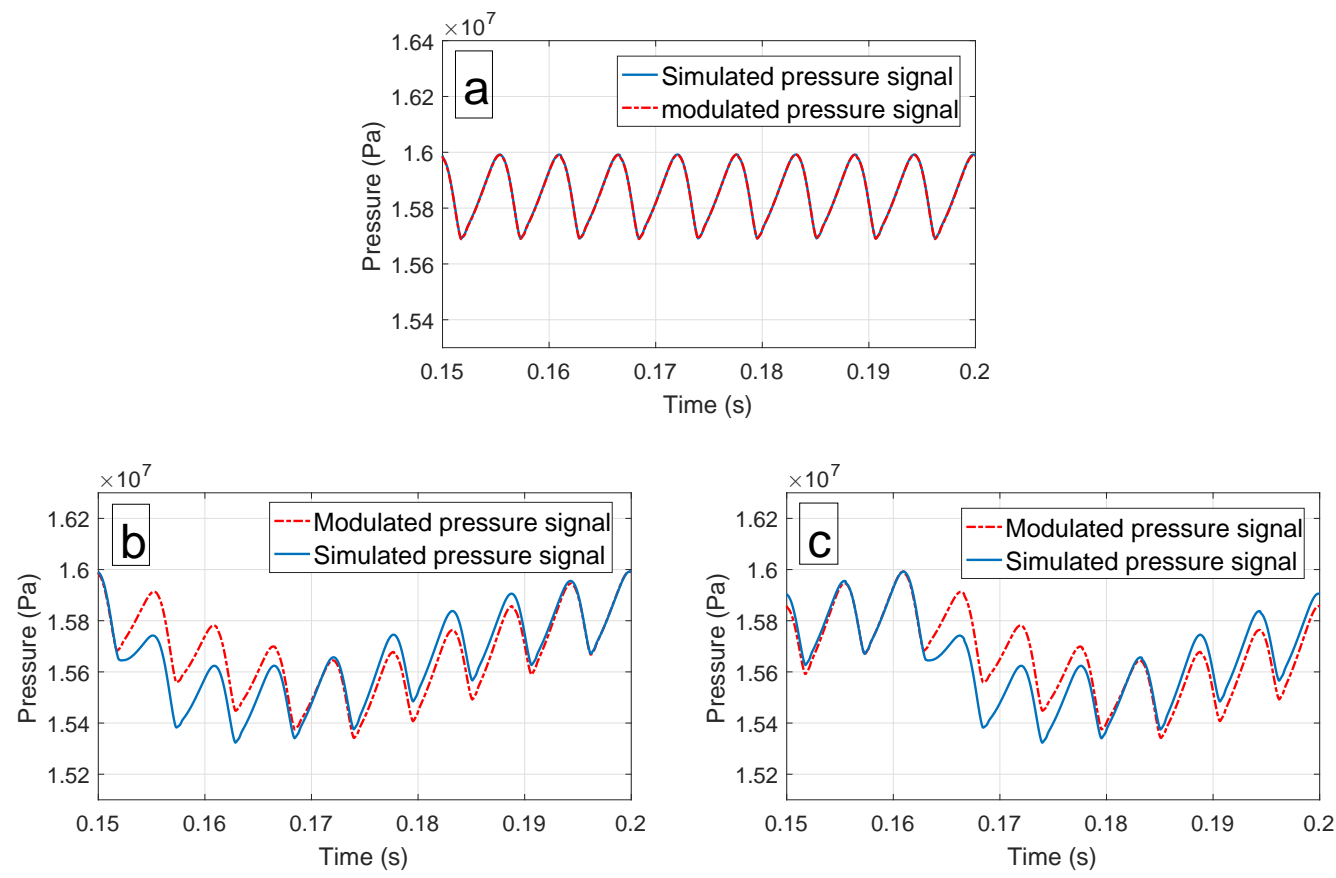

Figure 13: Modulated and simulated output pressure signals for: (a) healthy state, (b) piston 1 leaking, (c) piston 3 leaking. 


\subsection{Diagnosis decision}

The last step in a model-based fault diagnosis technique is the decision making using the generated residual signal. This decision can be done using a constant threshold or an adaptive one [20]. In our case, two thresholds are defined in order to implement the diagnosis decision algorithm. They represent respectively $1 \%$ and $10 \%$
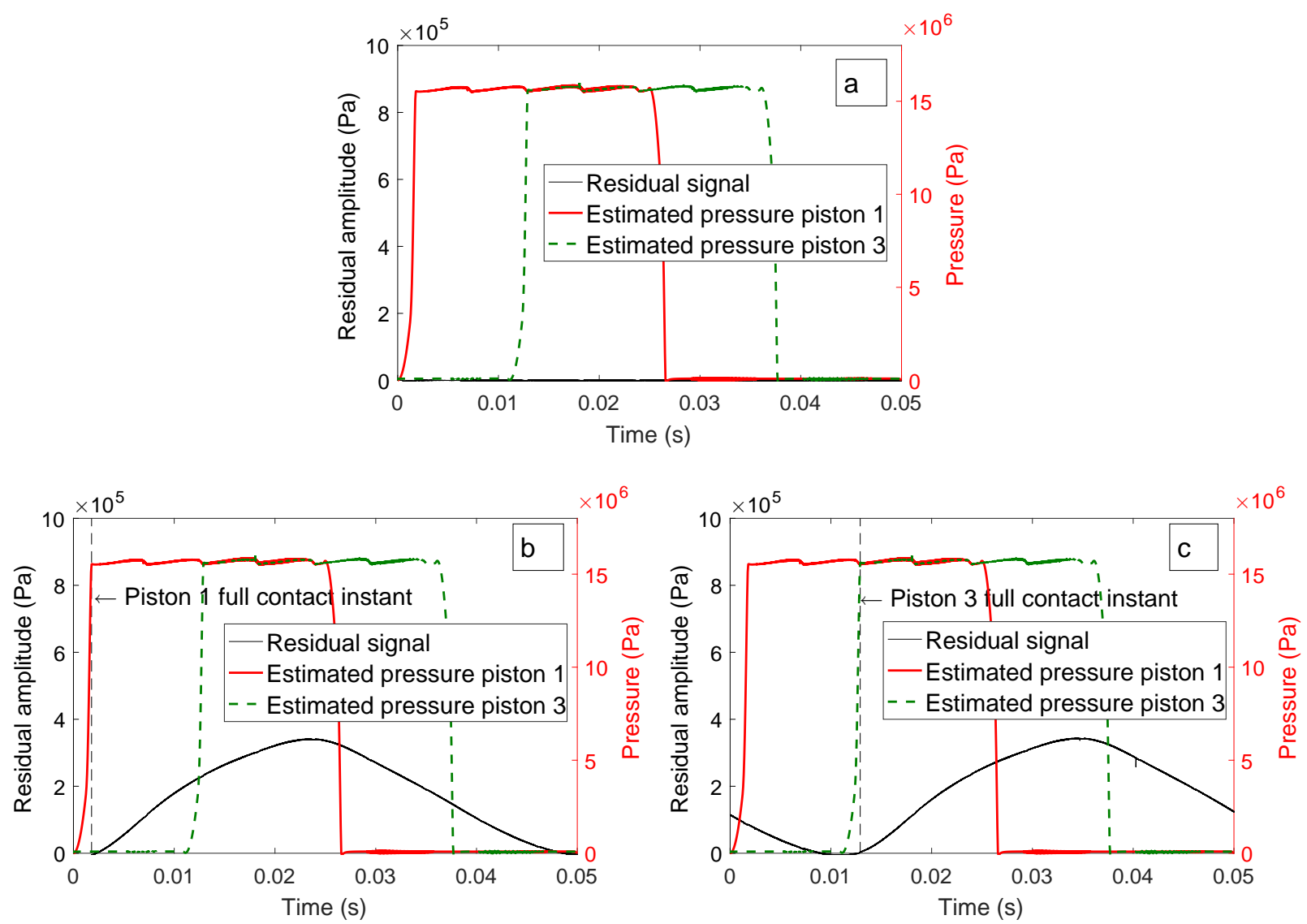

Figure 14: Residual signal and estimations pressure inside piston 1 and 3 for: (a) healthy state, (b) piston 1 leaking, (c) piston 3 leaking.

from the peak to peak value of the healthy output pressure signal. The peak to peak value is used because of its sensitivity to the presence of a piston leak. Indeed, the drop caused by a piston leak in the output pressure signal leads to an increase in the peak to peak value. Furthermore, we define $t_{0}$ as the piston 1 full contact instant and $T$ as the signal period (see figure 15). The diagnosis decision algorithm is presented in algorithm 1. 




Figure 15: Residual signal in presence of leak in piston 1.



\subsection{Case of simultaneous piston leaks}

In the previous sections, we have presented the effect of one piston leak on the output pressure signal, but what happens if more than one piston are leaking simultaneously? To answer this question we have conducted an experimentation using three worn pistons with different severities. We have chosen different worn severities to reflect the randomness of piston leaks occurrence. These severities are giving by $\delta_{p l 1}=\delta_{p}+40 \mu \mathrm{m}=8 \times 10^{-5} \mathrm{~m}$, $\delta_{p l 2}=\delta_{p}+20 \mu m=6 \times 10^{-5} \mathrm{~m}, \delta_{p l 3}=\delta_{p}+5 \mu \mathrm{m}=4.5 \times 10^{-5} \mathrm{~m}$. Figure 16 shows the disposition of the 3 worn pistons in the barrel. The first position in figure 16 refers to the first piston position with respect to the trigger.

In order to demonstrate the universality of the proposed method, we have changed the operating conditions 
of the first experiment. Indeed, the rotation speed has become $1450 \mathrm{rpm}$ (1200 rpm in the first experiment) and the load is changed so that the average pressure is around 137 bar (around 160 bar in the first experiment).

Figure 17 shows the obtained pressure signals when three pistons are leaking simultaneously. Figure 17a shows the obtained pressure signal when the big wear piston $\delta_{p l 1}$ is in the first position (see figure 16), the medium wear piston $\delta_{p l 2}$ is in the fourth position with respect to the direction of rotation and the small wear piston $\delta_{p l 3}$ is in the seventh position. At first sight, we note a concave drop similar to the one introduced by one piston leak (see figure 10). The same remark can be made for figure $17 \mathrm{~b}$ where piston $\delta_{p l 1}$ is in the fourth position, piston $\delta_{p l 2}$ is in seventh position and piston $\delta_{p l 3}$ is in the first position.

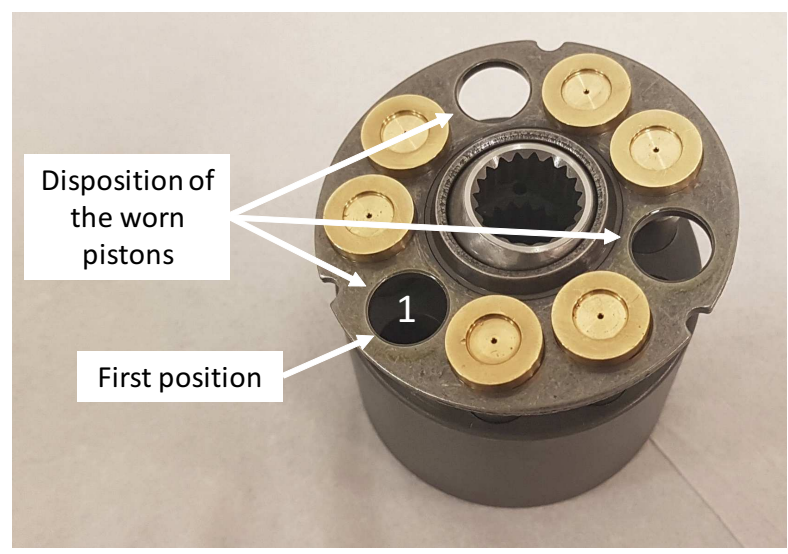

Figure 16: Disposition of the worn pistons in the barrel.
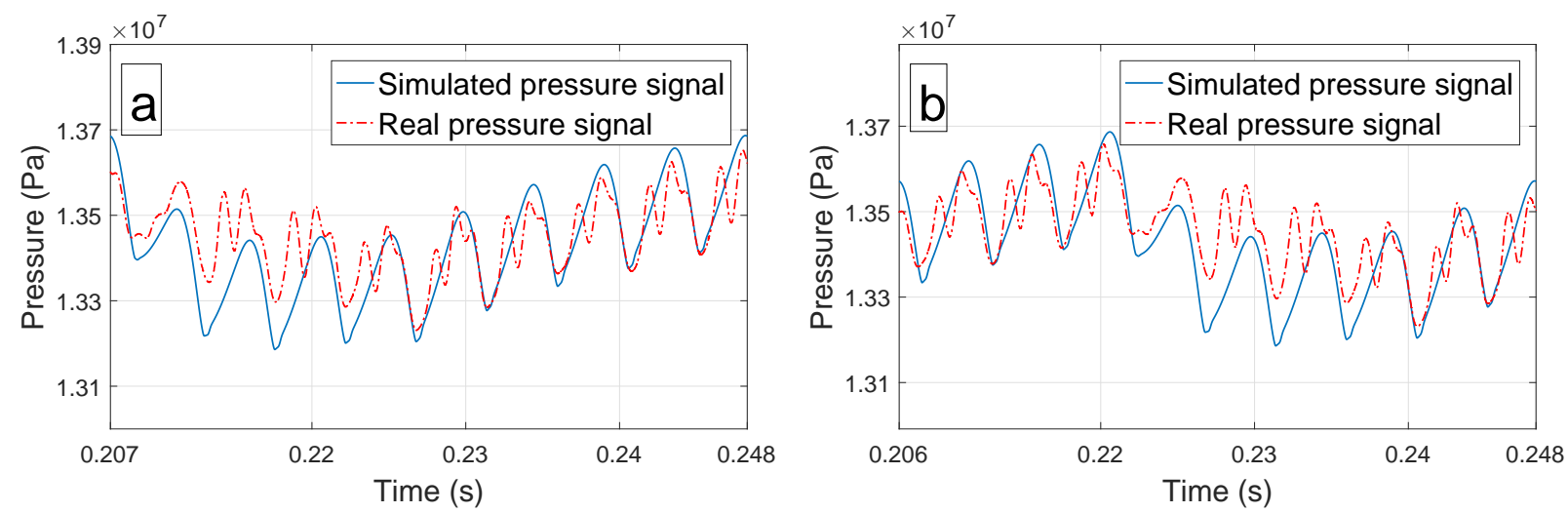

Figure 17: Real and simulated output pressure signals for: (a) big wear piston in the first position, (b) big wear piston in the fourth position.

Figure 18 shows the residual signal and estimated pressures inside piston 1 and 4 . Figure 18a concerns the case of piston $\delta_{p l 1}$ in the first position. It can be seen that the residual signal begins to increase when piston $\delta_{p l 1}$ is in full contact with the valve plate. We can note also the presence of deformations in the residual signal that wasn't noticeable in the one piston leak case. These deformations are introduced by the medium wear $\delta_{p l 2}$ and the small wears $\delta_{p l 3}$. The same remark can be made for figure 18a where we see an increase in the residual signal when piston $\delta_{p l 1}$ is in full contact with the valve plate.

Based on the residual signal and the contact instants of all pistons, it's possible to identify the big wear piston $\delta_{p l 1}$ using algorithm 1 . However, the identification of the two remaining worn pistons is more complicated 
because the decision criterion is not obvious. We can conclude that the proposed method is able to identify the piston with the largest defect when there is a multitude of pistons leaking simultaneously.


Figure 18: Residual signal and estimations of pressure inside piston 1 and 4 for: (a) big wear piston in the first position, (b) big wear piston in the fourth position.

\section{Conclusion}

This paper presents a new model-based fault diagnosis method able to identify the leaky piston in an APP. This method implies mathematical modelling of the system under investigation. Therefore, a mathematical model of an APP is presented and implemented on Simulink. Otherwise, An experimental test bench is used to perform leakage tests. Output pressure signals are acquired in the healthy condition and in presence of piston leaks. Simulated output pressure signals are compared with real output pressure signals for different health states to showcase the model's robustness.

The EKF was adapted in order to identify the leaky piston among the good ones. Firstly, the EKF is used to estimate piston chamber pressures and the output pressure of the pump. Then, a residual signal is calculated using the EKF inputs and outputs. Finally, the residual signal is used along with estimated piston chamber pressures to make the diagnosis decision. The presented results show the efficiency of the proposed approach.

In the case of simultaneous piston leaks with different severities, the proposed method is able to identify the piston with the largest defect, offering the possibility of replacing it and therefore preserving the installation from significant damage.

\section{Acknowledgments}

The authors would like to thank Bpifrance for the financial support. 


\section{Appendix A Nomenclature}

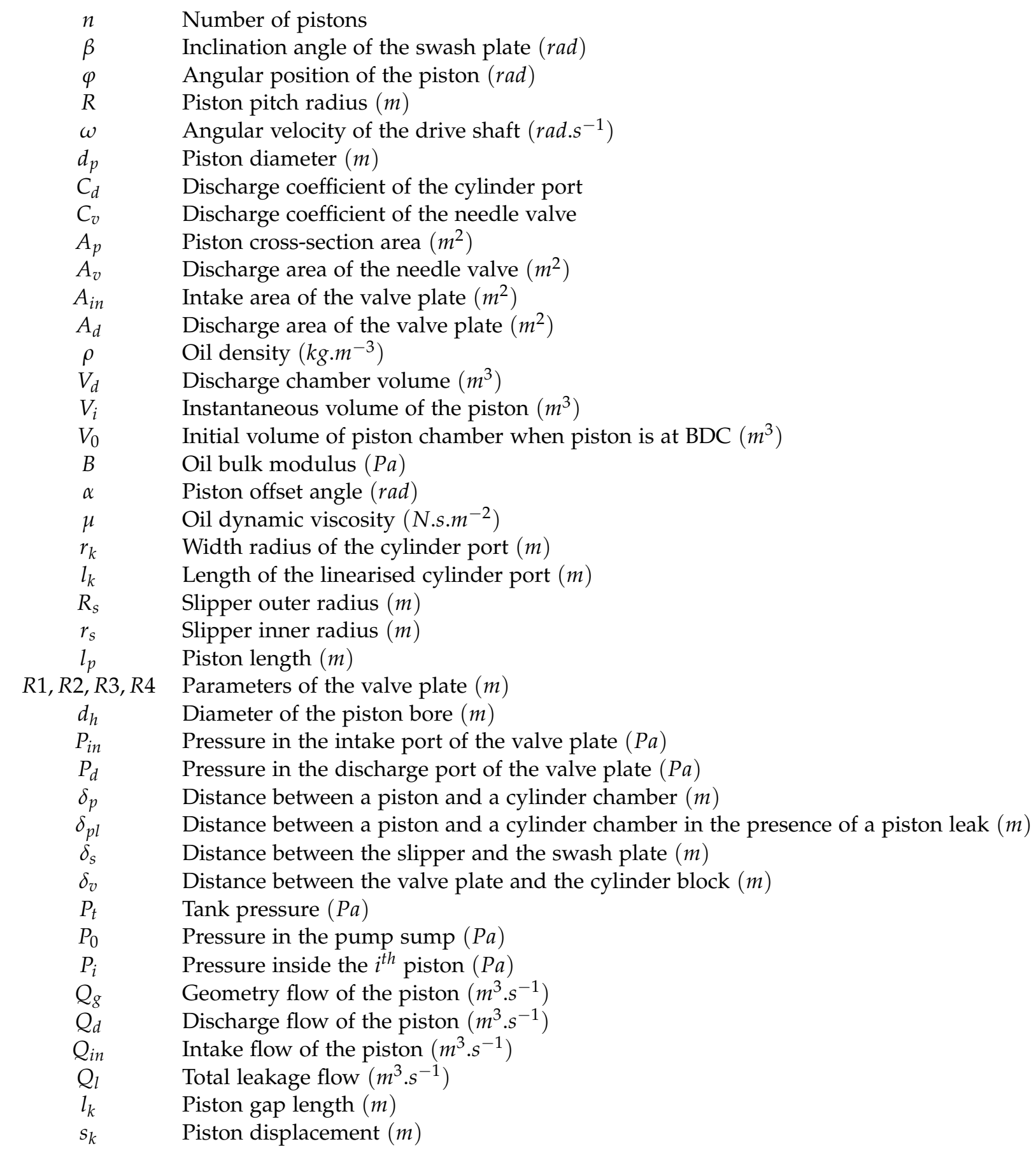




\section{References}

[1] F.-1. Yin, S.-l. Nie, S.-h. Xiao, W. Hou, Numerical and experimental study of cavitation performance in sea water hydraulic axial piston pump, Proceedings of the Institution of Mechanical Engineers, Part I: Journal of Systems and Control Engineering 230 (8) (2016) 716-735.

[2] H. Chen, P. S. Chua, G. Lim, Adaptive wavelet transform for vibration signal modelling and application in fault diagnosis of water hydraulic motor, Mechanical Systems and Signal Processing 20 (8) (2006) 2022-2045.

[3] H. Chen, P. S. Chua, G. Lim, Fault degradation assessment of water hydraulic motor by impulse vibration signal with wavelet packet analysis and kolmogorov-smirnov test, Mechanical Systems and Signal Processing 22 (7) (2008) 1670-1684.

[4] S. Wang, J. Xiang, H. Tang, X. Liu, Y. Zhong, Minimum entropy deconvolution based on simulationdetermined band pass filter to detect faults in axial piston pump bearings, ISA transactions 88 (2019) 186-198.

[5] M. Zhonghai, W. Shaoping, S. Jian, L. Tongyang, W. Xingjian, Fault diagnosis of an intelligent hydraulic pump based on a nonlinear unknown input observer, Chinese Journal of Aeronautics 31 (2) (2018) 385-394.

[6] W. Zhao, Z. Wang, J. Ma, L. Li, Fault diagnosis of a hydraulic pump based on the ceemd-stft time-frequency entropy method and multiclass svm classifier, Shock and Vibration 2016.

[7] J. Du, S. Wang, H. Zhang, Layered clustering multi-fault diagnosis for hydraulic piston pump, Mechanical Systems and Signal Processing 36 (2) (2013) 487-504.

[8] P. Casoli, A. Bedotti, F. Campanini, M. Pastori, A methodology based on cyclostationary analysis for fault detection of hydraulic axial piston pumps, Energies 11 (7) (2018) 1874.

[9] P. Casoli, M. Pastori, F. Scolari, M. Rundo, A vibration signal-based method for fault identification and classification in hydraulic axial piston pumps, Energies 12 (5) (2019) 953.

[10] Y. Lan, J. Hu, J. Huang, L. Niu, X. Zeng, X. Xiong, B. Wu, Fault diagnosis on slipper abrasion of axial piston pump based on extreme learning machine, Measurement 124 (2018) 378-385.

[11] H. Yu, H. Li, Y. Li, Y. Li, A novel improved full vector spectrum algorithm and its application in multi-sensor data fusion for hydraulic pumps, Measurement 133 (2019) 145-161.

[12] J. Bergada, S. Kumar, D. L. Davies, J. Watton, A complete analysis of axial piston pump leakage and output flow ripples, Applied Mathematical Modelling 36 (4) (2012) 1731-1751.

[13] J. Ivantysyn, M. Ivantysynova, Hydrostatic pumps and motors: principles, design, performance, modelling, analysis, control and testing, Tech Books International, 2003.

[14] Z. E. Li, Condition monitoring of axial piston pump, Ph.D. thesis (2005).

[15] J. J. Palazzolo, L. D. Scheunemann, J. R. Hartin, Leakage fault detection method for axial-piston variable displacement pumps, in: 2008 IEEE Aerospace Conference, IEEE, 2008, pp. 1-8.

[16] Q. Gao, H. Tang, J. Xiang, Y. Zhong, S. Ye, J. Pang, A walsh transform-based teager energy operator demodulation method to detect faults in axial piston pumps, Measurement 134 (2019) 293-306.

[17] M. Ivantysynova, The piston cylinder assembly in piston machines-a long journey of discovery, in: Proceedings of 8th IFK international conference on fluid power, Dresden, Germany, Vol. 3, 2012, pp. $307-332$. 
[18] Z. Gao, C. Cecati, S. X. Ding, A survey of fault diagnosis and fault-tolerant techniques-part i: Fault diagnosis with model-based and signal-based approaches, IEEE Transactions on Industrial Electronics 62 (6) (2015) 3757-3767.

[19] R. Liu, B. Yang, E. Zio, X. Chen, Artificial intelligence for fault diagnosis of rotating machinery: A review, Mechanical Systems and Signal Processing 108 (2018) 33-47.

[20] J. Chen, R. J. Patton, Robust model-based fault diagnosis for dynamic systems, Vol. 3, Springer Science \& Business Media, 2012.

[21] M. S. Grewal, Kalman filtering, Springer, 2011.

[22] M. Bressel, M. Hilairet, D. Hissel, B. O. Bouamama, Extended kalman filter for prognostic of proton exchange membrane fuel cell, Applied Energy 164 (2016) 220-227.

[23] B. Zhang, J. Ma, H. Hong, H. Yang, Y. Fang, Analysis of the flow dynamics characteristics of an axial piston pump based on the computational fluid dynamics method, Engineering Applications of Computational Fluid Mechanics 11 (1) (2017) 86-95.

[24] S. Ye, J. Zhang, B. Xu, W. Song, L. Chen, H. Shi, S. Zhu, Experimental and numerical studies on erosion damage in damping holes on the valve plate of an axial piston pump, Journal of Mechanical Science and Technology 31 (9) (2017) 4285-4295.

[25] C. Guan, Z. Jiao, S. He, Theoretical study of flow ripple for an aviation axial-piston pump with damping holes in the valve plate, Chinese Journal of Aeronautics 27 (1) (2014) 169-181.

[26] F. Yin, S. Nie, W. Hou, S. Xiao, Effect analysis of silencing grooves on pressure and vibration characteristics of seawater axial piston pump, Proceedings of the Institution of Mechanical Engineers, Part C: Journal of Mechanical Engineering Science 231 (8) (2017) 1390-1409.

[27] B. Xu, S. Ye, J. Zhang, C. Zhang, Flow ripple reduction of an axial piston pump by a combination of cross-angle and pressure relief grooves: Analysis and optimization, Journal of Mechanical Science and Technology 30 (6) (2016) 2531-2545.

[28] J. Huang, Z. Yan, L. Quan, Y. Lan, Y. Gao, Characteristics of delivery pressure in the axial piston pump with combination of variable displacement and variable speed, Proceedings of the Institution of Mechanical Engineers, Part I: Journal of Systems and Control Engineering 229 (7) (2015) 599-613. 